\title{
Body mass index in Australian children: recent changes and relevance of ethnicity
}

\author{
Judith Lynch, Xing Li Wang, David E L Wilcken
}

\begin{abstract}
Aim-To determine changes over time in the body mass index (BMI) profile of Australian primary schoolchildren and to assess the effects of sex and ethnicity. Methods-Height and weight were measured in 3645 children (1869 girls and 1596 boys), aged 5-12 years from 39 schools in southeastern Sydney during 1994-7. Levels in the four largest ethnic groups of the population were compared with those measured by the 1985 Australian Council on Health, Physical Education, and Recreation (ACHPER) survey.

Results-The study population was $\mathbf{5 9 . 9 \%}$ white (north European), 8.5\% Mediterranean white, $7.7 \%$ Asian, $7.7 \%$ other, and $16.2 \%$ mixed (mainly Asian-white (36\%) and Arab-white (24.7\%)). There were sufficient numbers in four groups for analysis and comparison with the ACHPER survey: Mediterranean white, other white, mixed ethnicity, and Asian children. The age and sex adjusted BMI was highest in Mediterranean white, then white, mixed race, and Asian children. There were minimal differences between sexes within each group. However, boys had an age and sex adjusted BMI 1.5-6.5\% higher (mean, $3.9 \%$ ) than in ACHPER in 1985, as did white girls (mean increase, $2.4 \%$ ). Conclusions-BMI in southeastern Sydney schoolchildren is related strongly to ethnicity and age; in boys and white girls it is on average $3.9 \%$ and $2.4 \%$ greater, respectively, than that recorded in the 1985 ACHPER survey. We suggest that this 10 year increase reflects a general trend in developed countries. Because increased BMI in childhood tracks to adulthood and is then associated with adverse effects on health, these findings signal a need for prevention.

(Arch Dis Child 2000;82:16-20)
\end{abstract}

Department of

Cardiovascular

Medicine, Ground

Floor, South Wing,

Edmund Blacket

Building, The Prince

of Wales Hospital,

Randwick, NSW 2031, Australia

J Lynch

X L Wang

D E L Wilcken

Correspondence to:

Professor Wilcken

email: d.wilcken $a$

unsw.edu.au

Accepted 18 August 1999 childhood tracks to adulthood and refle subsequent adult values. ${ }^{23}$ In the course of an ongoing family based heart health education
Obesity is an increasing health problem in chological disturbances are well documented and attest to its adverse consequences for individuals, and for national health budgets. ${ }^{1}$ It is now known that increased body weight in programme we recently reported data suggesting that weight relative to height, the body mass index (BMI), has increased over the past 10 years in Australian children. ${ }^{4}$ In view of the possible long term consequences of this we have undertaken an expanded study to characterise more fully the current profile of weight relative to height in Australian primary school aged children, specifically to explore sex and ethnicity differences. The results define these differences and provide evidence indicating that during the past 12 years there has been a significant increase in the number of overweight boys and a similar trend in girls.

\section{Methods}

Between the middle of 1994 and 1997 we approached 42 primary schools in the southeastern Sydney area and received permission from 39 to offer our risk factor screening programme ("the heart health education programme") to all 5-12 year olds. These children were part of a larger group for whom lipid profiles have already been reported, ${ }^{5}$ and were the ones whose height and weight were also measured. We began recording height and weight midway through the programme.

Over the three years we assessed 3499 children, of whom we have complete information on 3465: 1596 boys (46.1\%) and 1869 girls $(53.9 \%)$ aged $5-12$ years in government primary $(31.6 \%)$, Catholic primary $(37.6 \%)$, and private fee paying $(30.8 \%)$ schools in the area. The ethnicity of each child was established initially from the consent form sent home to all parents. This was confirmed by asking the ethnic origin of each parent on a family history questionnaire, which was mailed to the home of each child directly after testing at school. This asked specifically the country of origin of each parent's family, and from this we determined the ethnicity of the child.

The risk factors screened for and the nature of the family history questionnaire have been detailed and the results reported elsewhere ${ }^{4-6}$; however, in this group we also measured the height and weight of each of the children tested. By dividing the weight $(\mathrm{kg})$ by the square of the height (m) we calculated the BMI. The children's BMI values were compared with the data obtained from the 1985 Australian Council on Health, Physical Education, and Recreation (ACHPER) survey of over 8000 randomly selected Australian schoolchildren. ${ }^{7}$

To explore the possibility of any bias in our population introduced by assessing only children whose parents had consented to fingerprick blood lipid testing, as opposed to a random population, we measured the height 
and weight of all the children in the age range in nine consecutive participating schools. This allowed us to compare the BMIs of children whose parents had and had not given permission for fingerprick blood testing. A total of 796 children were included in this sample; 331 $(41.6 \%)$ without blood testing ( $54 \%$ boys, $46 \%$ girls) and $465(58.4 \%)$ with blood testing ( $47 \%$ boys and $53 \%$ girls). There were no BMI differences between the boys and girls of the two groups.

Our study was approved by the ethics committee of the University of New South Wales.

\section{Statistical analysis}

Values for measured variables are presented as means (SEM). Student's $t$ tests were used for comparisons between groups and an ANOVA $F$ test for more than two groups for quantitative variables. As expected, distributions of the BMI in the total population and in boys and girls were skewed. However, in the subgroups divided by age, sex, and ethnicity the BMIs were normally distributed, with no significant difference in the variances between groups. Thus, we used parametric comparisons for the subgroup analysis. We used a general factorial model of ANOVA to assess the main and interactive effects of age, sex, and ethnicity on the variance of BMI in children. Two tailed $p$ values are reported for the significance of tests.

\section{Results}

EFFECT OF AGE AND SEX ON BMI

Because ethnicity might have a significant influence on children's BMI, we assessed the effects of age and sex on BMI in each ethnic group. The ethnic distribution of the pupils screened was $59.9 \%$ white (north European), 7.7\% Asian, 8.5\% Mediterranean white, and

Table 1 Relation between age and BMI (mean (SEM)) in four different ethnic groups

\begin{tabular}{|c|c|c|c|c|}
\hline Age & Asian & White & Mediterranean & Mixed ethnicity \\
\hline \multicolumn{5}{|l|}{ Boys } \\
\hline 6 & $\begin{array}{l}16.25(0.57) \\
(\mathrm{n}=9)\end{array}$ & $\begin{array}{l}15.67(0.16) \\
(\mathrm{n}=85)\end{array}$ & $\begin{array}{l}16.02(0.99) \\
(\mathrm{n}=7)\end{array}$ & $\begin{array}{l}16.35(0.36) \\
(\mathrm{n}=27)\end{array}$ \\
\hline 7 & $\begin{array}{l}15.81(0.44) \\
(\mathrm{n}=25)\end{array}$ & $\begin{array}{l}16.11(0.12) \\
(\mathrm{n}=200)\end{array}$ & $\begin{array}{l}17.21(0.42) \\
(\mathrm{n}=25)\end{array}$ & $\begin{array}{l}16.92(0.31) \\
(\mathrm{n}=52)\end{array}$ \\
\hline 8 & $\begin{array}{l}15.77(0.34) \\
(\mathrm{n}=21)\end{array}$ & $\begin{array}{l}16.76(0.17) \\
(\mathrm{n}=166)\end{array}$ & $\begin{array}{l}17.69(0.55) \\
(\mathrm{n}=28)\end{array}$ & $\begin{array}{l}17.16(0.42) \\
(\mathrm{n}=46)\end{array}$ \\
\hline 9 & $\begin{array}{l}16.34(0.61) \\
(\mathrm{n}=21)\end{array}$ & $\begin{array}{l}17.04(0.15) \\
(\mathrm{n}=217)\end{array}$ & $\begin{array}{l}19.38(0.56) \\
(\mathrm{n}=26)\end{array}$ & $\begin{array}{l}17.06(0.28) \\
(\mathrm{n}=52)\end{array}$ \\
\hline 10 & $\begin{array}{l}17.49(0.65) \\
(\mathrm{n}=19)\end{array}$ & $\begin{array}{l}17.66(0.18) \\
(\mathrm{n}=184)\end{array}$ & $\begin{array}{l}19.67(0.62) \\
(\mathrm{n}=33)\end{array}$ & $\begin{array}{l}17.68(0.44) \\
(\mathrm{n}=53)\end{array}$ \\
\hline 11 & $\begin{array}{l}18.48(0.73) \\
(\mathrm{n}=19)\end{array}$ & $\begin{array}{l}18.34(0.39) \\
(\mathrm{n}=76)\end{array}$ & $\begin{array}{l}21.34(1.12) \\
(\mathrm{n}=10)\end{array}$ & $\begin{array}{l}18.81(0.58) \\
(\mathrm{n}=23)\end{array}$ \\
\hline 12 & $\begin{array}{l}20.50(1.19) \\
(\mathrm{n}=8)\end{array}$ & $\begin{array}{l}19.61(0.83) \\
(\mathrm{n}=19)\end{array}$ & $\begin{array}{l}21.88 \\
(\mathrm{n}=1)\end{array}$ & $\begin{array}{l}18.24(1.97) \\
(\mathrm{n}=3)\end{array}$ \\
\hline \multicolumn{5}{|c|}{ (in - o) } \\
\hline 6 & $\begin{array}{l}16.15(0.70) \\
(\mathrm{n}=16)\end{array}$ & $\begin{array}{l}15.76(0.16) \\
(\mathrm{n}=116)\end{array}$ & $\begin{array}{l}16.66(0.77) \\
(\mathrm{n}=11)\end{array}$ & $\begin{array}{l}16.27(0.39) \\
(\mathrm{n}=33)\end{array}$ \\
\hline 7 & $\begin{array}{l}15.45(0.48) \\
(\mathrm{n}=24)\end{array}$ & $\begin{array}{l}16.31(0.14) \\
(\mathrm{n}=205)\end{array}$ & $\begin{array}{l}17.79(0.48) \\
(\mathrm{n}=29)\end{array}$ & $\begin{array}{l}16.42(0.29) \\
(\mathrm{n}=64)\end{array}$ \\
\hline 8 & $\begin{array}{l}16.34(0.40) \\
(\mathrm{n}=32)\end{array}$ & $\begin{array}{l}16.84(0.17) \\
(\mathrm{n}=196)\end{array}$ & $\begin{array}{l}17.65(0.35) \\
(\mathrm{n}=39)\end{array}$ & $\begin{array}{l}16.76(0.34) \\
(\mathrm{n}=52)\end{array}$ \\
\hline 9 & $\begin{array}{l}16.94(0.78) \\
(\mathrm{n}=27)\end{array}$ & $\begin{array}{l}17.54(0.18) \\
(\mathrm{n}=215)\end{array}$ & $\begin{array}{l}18.46(0.50) \\
(\mathrm{n}=30)\end{array}$ & $\begin{array}{l}17.51(0.43) \\
(\mathrm{n}=53)\end{array}$ \\
\hline 10 & $\begin{array}{l}17.11(0.50) \\
(\mathrm{n}=24)\end{array}$ & $\begin{array}{l}18.14(0.21) \\
(\mathrm{n}=209)\end{array}$ & $\begin{array}{l}18.36(0.47) \\
(\mathrm{n}=38)\end{array}$ & $\begin{array}{l}18.46(0.43) \\
(\mathrm{n}=50)\end{array}$ \\
\hline 11 & $\begin{array}{l}17.71(0.64) \\
(n=15)\end{array}$ & $\begin{array}{l}18.25(0.22) \\
(\mathrm{n}=138)\end{array}$ & $\begin{array}{l}18.80(0.69) \\
(\mathrm{n}=16)\end{array}$ & $\begin{array}{l}18.89(0.58) \\
(\mathrm{n}=42)\end{array}$ \\
\hline 12 & $\begin{array}{l}17.81(1.50) \\
(\mathrm{n}=4)\end{array}$ & $\begin{array}{l}19.34(0.48) \\
(\mathrm{n}=34)\end{array}$ & $\begin{array}{l}19.55(0.72) \\
(\mathrm{n}=2)\end{array}$ & $\begin{array}{l}18.41(0.42) \\
(\mathrm{n}=10)\end{array}$ \\
\hline
\end{tabular}

There are significant linear correlations between age and BMI in each of the four ethnic groups the $\mathrm{p}$ values are $<0.0001$ for a separate analysis in each of the four groups.
Table 2 Age adjusted BMI (mean (SEM)) according to ethnic origin

\begin{tabular}{lll}
\hline Ethnicity & Boys & Girls \\
\hline Asian & $16.82(0.24)$ & $16.68(0.23)$ \\
& $(\mathrm{n}=123)$ & $(\mathrm{n}=145)$ \\
White & $16.99(0.07)$ & $17.22(0.07)$ \\
& $(\mathrm{n}=956)$ & $(\mathrm{n}=1118)$ \\
Mediterranean & $18.64(0.25)$ & $18.06(0.22)$ \\
& $(\mathrm{n}=131)$ & $(\mathrm{n}=165)$ \\
Mixed ethnicity & $17.30(0.17)$ & $17.30(0.12)$ \\
& $(\mathrm{n}=259)$ & $(\mathrm{n}=305)$ \\
\hline
\end{tabular}

The age adjusted BMIs were evaluated under each univariate analysis of variance model for each two group comparison in which age was entered into the model as a covariate. Age was significantly correlated with BMI in all four subgroup analyses. The mean ages adjusted to were 8.6, 8.6, 8.7, and 8.6 years for comparisons between boys and girls in Asian, white, Mediterranean, and mixed race groups, respectively.

The powers (and significance) of comparisons between girls and boys in Asian, white, Mediterranean, and mixed ethnicity groups were 0.071 (0.670), 0.598 (0.027), 0.398 (0.089), and 0.057 (0.809), respectively.

$16.2 \%$ mixed ethnicity, with the remaining $7.7 \%$ comprising other smaller ethnic groups; those of mixed ethnicity were principally Asian-white (36.0\% of the mixed population) and Arab-white $24.7 \%$ of the mixed population). The remaining $7.7 \%$ among the groups contained small numbers of children of five different ethnicities, Arab ( $\mathrm{n}=99)$, black $(\mathrm{n}=$ $4)$, Indian ( $n=46)$, Pacific Islander $(n=43)$ and South American ( $\mathrm{n}=70)$; these numbers did not provide sufficient power to detect the measured effects and were excluded. Therefore, we conducted our analyses among the four ethnic groups from the southeastern Sydney area for whom there were measurements in a sufficient number of subjects, and for whom there were data available for comparison from the ACHPER 1985 survey. These were the white (north European), Mediterranean white, Asian, and mixed ethnicity groups.

The age distribution of the studied population was from 5 to 13 years, with most aged 6-11. Age was calculated from the date of birth and rounded to the closest year; that is, $<0.5$ was rounded down to the year below and $\geqslant 0.5$ was rounded up to the year above. There was a linear increase in BMI with age in both girls and boys for each ethnic group (table 1) and in each of the four ethnic groups age was a significant predictor of the BMI $(p<0.0001)$ in both boys and girls. However, except for white children $(p=0.027)$, there was no significant sex effect on BMI in each ethnic group after controlling for age as a covariate ( $p=0.670$ for Asians; $p=0.089$ for Mediterraneans; $p=0.809$ for those of mixed race). As shown in table 2, the differences between girls and boys within each of the four ethnic groups were minimal.

EFFECT OF ETHNICITY ON BMI

As seen in table 2, in both girls and boys among the four ethnic groups, those of Asian ethnicity had the lowest BMI and those of Mediterranean ethnicity the highest. The differences remained significant after controlling for age in the univariate analysis of variance model $(\mathrm{F}=17.425$, degrees of freedom $(\mathrm{df})=3$, $\mathrm{p}=0.0001$ for boys; $\mathrm{F}=7.544, \mathrm{df}=3$, $\mathrm{p}=0.0001$ for girls). 
COMPARISON OF OUR POPULATION OF CHILDREN WITH THAT OF ACHPER IN 1985

We compared the BMI differences among our present population of children with those of the ACHPER 1985 population ${ }^{7}$ in girls and boys for each of these four ethnic groups (table 3). There were some differences in the distribution of ethnicities between the two populations, although this may be more apparent than real, and a result of differences in data collection techniques. The ACHPER survey recorded parental birthplace, which might not always reflect ethnicity; we determined ethnicity by asking parents for their family's country of origin (see methods). However, it is relevant that the percentage of children whose parents were Mediterranean was the same in both populations; in ACHPER it was $9.8 \%$ and in our population $8.6 \%$. It is noteworthy too that there was a much higher proportion of Asian children in our study $(7.5 \%)$ than in the ACHPER survey $(1.5 \%)$. Nevertheless, the increase in BMI over the 10-12 year period was consistent. There was an average increase of $3.9 \%$ for all ethnic groups in boys but of only $1.2 \%$ in girls (table 3 ). Although age was a significant independent predictor of BMI in both populations, the difference in BMI between the current and ACHPER studies remained significant after controlling for age (table 3). Table 4 shows age related BMI for white boys and girls in the ACHPER study and our study. The BMI is consistently higher in our study population.

Table 3 Age adjusted BMI (mean (SEM)) according to ethnic origin and compared to those for ACHPER in 1985

\begin{tabular}{|c|c|c|c|c|}
\hline \multirow[b]{2}{*}{ Ethnicity } & \multicolumn{2}{|l|}{ Boys } & \multicolumn{2}{|l|}{ Girls } \\
\hline & ACHPER 85 & Sydney 98 & ACHPER 85 & Sydney 98 \\
\hline Asian & $\begin{array}{l}16.20(0.50) \\
(\mathrm{n}=35)\end{array}$ & $\begin{array}{l}17.25(0.21) \dagger \\
(\mathrm{n}=123)\end{array}$ & $\begin{array}{l}17.03(0.45) \\
(\mathrm{n}=54)\end{array}$ & $\begin{array}{l}16.96(0.25) \\
(\mathrm{n}=145)\end{array}$ \\
\hline White & $\begin{array}{l}17.92(0.05) \\
(\mathrm{n}=2441\end{array}$ & $\begin{array}{l}18.32(0.09)^{\star \star \star} \\
(\mathrm{n}=956)\end{array}$ & $\begin{array}{l}18.21(0.05) \\
(\mathrm{n}=2387)\end{array}$ & $\begin{array}{l}18.70(0.09)^{\star \star \star} \\
(\mathrm{n}=1118)\end{array}$ \\
\hline Mediterranean & $\begin{array}{l}19.40(0.23) \\
(\mathrm{n}=243)\end{array}$ & $\begin{array}{l}20.45(0.35)^{\star} \\
(\mathrm{n}=131\end{array}$ & $\begin{array}{l}18.82(0.23) \\
(\mathrm{n}=184)\end{array}$ & $\begin{array}{l}18.99(0.25) \\
(\mathrm{n}=165)\end{array}$ \\
\hline Mixed ethnicity & $\begin{array}{l}17.83(0.24) \\
(\mathrm{n}=210)\end{array}$ & $\begin{array}{l}18.09(0.21) \\
(\mathrm{n}=259)\end{array}$ & $\begin{array}{l}17.77(0.23) \\
(\mathrm{n}=195)\end{array}$ & $\begin{array}{l}18.08(0.17) \\
(\mathrm{n}=305)\end{array}$ \\
\hline
\end{tabular}

Age adjusted BMIs were evaluated under each univariate analysis of variance model for each two group comparison in which age was entered into the model as a covariate. The age was significantly correlated with BMI in all eight subgroup analysis.

The mean ages adjusted to were 9.2,11.0,11.2, and 10.1 years for comparisons in boys in Asian, white, Mediterranean, and mixed ethnicity groups, respectively; and 9.3, 10.9, 10.4, and 9.8 years for corresponding comparisons in girls.

The powers (and significance) of comparisons for boys in Asian, white, Mediterranean, and mixed ethnicity groups were $0.443(\dagger 0.070), 0.925\left({ }^{\star \star \star} 0.001\right), 0.586\left({ }^{\star} 0.030\right)$ and $0.105(0.492)$ and for the same groups in girls $0.052(0.900), 0.981\left({ }^{\star \star \star} 0.0001\right), 0.071(0.672)$ and $0.164(0.329)$, respectively. (Age breakdown comparisons are available upon request.)

Table 4 BMI (mean (SEM)) for white children compared to those for ACHPER in 1985 in each age category

\begin{tabular}{|c|c|c|c|c|}
\hline \multirow[b]{2}{*}{ Age } & \multicolumn{2}{|l|}{ Boys } & \multicolumn{2}{|l|}{ Girls } \\
\hline & ACHPER 85 & Sydney 98 & ACHPER 85 & Sydney 98 \\
\hline 9 & $\begin{array}{l}16.99(0.11) \\
(\mathrm{n}=345)\end{array}$ & $\begin{array}{l}17.04(0.15) \\
(\mathrm{n}=217)\end{array}$ & $\begin{array}{l}17.06(0.11) \\
(\mathrm{n}=335)\end{array}$ & $\begin{array}{l}17.54(0.18)^{\star} \\
(\mathrm{n}=215)\end{array}$ \\
\hline 10 & $\begin{array}{l}17.17(0.11) \\
(\mathrm{n}=345)\end{array}$ & $\begin{array}{l}17.66(0.18)^{\star} \\
(\mathrm{n}=184)\end{array}$ & $\begin{array}{l}17.56(0.12) \\
(\mathrm{n}=357)\end{array}$ & $\begin{array}{l}18.14(0.21)^{\star} \\
(\mathrm{n}=209)\end{array}$ \\
\hline 11 & $\begin{array}{l}17.92(0.13) \\
(\mathrm{n}=339)\end{array}$ & $\begin{array}{l}18.34(0.39) \\
(\mathrm{n}=76)\end{array}$ & $\begin{array}{l}18.17(0.15) \\
(\mathrm{n}=348)\end{array}$ & $\begin{array}{l}18.25(0.22) \\
(\mathrm{n}=138)\end{array}$ \\
\hline 12 & $\begin{array}{l}18.36(0.13) \\
(\mathrm{n}=364)\end{array}$ & $\begin{array}{l}19.61(0.83)^{\star} \\
(\mathrm{n}=19)\end{array}$ & $\begin{array}{l}18.65(0.14) \\
(\mathrm{n}=366)\end{array}$ & $\begin{array}{l}19.34(0.48) \\
(\mathrm{n}=34)\end{array}$ \\
\hline
\end{tabular}

${ }^{\star} \mathrm{p}<0.05$, Student's $t$ test.

\section{Discussion}

The BMI findings for the diverse ethnic groups in our study demonstrate substantial differences occurring in a stable but cosmopolitan community setting. Previous studies comparing different communities have shown the same ethnic differences. In a comprehensive recent review of more than 66000 healthy children from the USA aged 5-17 years (from nine studies) the centiles of BMI in each ethnic group were, from highest to lowest, Hispanic boys and girls, followed by all other white children, with Asian children having the lowest values. ${ }^{8}$ In adults also, European studies have consistently identified higher BMI values and obesity in southern versus northern European adults, ${ }^{9}$ with generally lower BMI values in Asians $^{10}$ and larger BMI values in the Arab population. ${ }^{11}$ In each of our four groups of children there was a linear increase in BMI with age, consistent with the findings at the same age in other populations. ${ }^{812}$ Clearly, our overall findings result from the effects on growth of both genetic and environmental impacts, but with recent changes an effect of the latter.

We emphasise that the urban population we surveyed contains a socioeconomic mix of privileged and less privileged families; and most of the "private" schools were Catholic parish schools. Moreover there were no BMI differences between individual schools after controlling for ethnicity. It seems likely therefore that our findings are representative of the national urban pattern. Indeed, they might underestimate the change because, paradoxically, there are data consistent with adiposity being more common among the less privileged in developed countries, both in children ${ }^{13}$ and in adults. ${ }^{14}$ Surveys of other communities should be undertaken.

Because of the size and ethnic diversity of the population studied by the ACHPER group, we compared our current age and sex adjusted findings with those of the ACHPER survey of 1985 to explore possible time related BMI changes; the results show an increased BMI in boys, with a similar trend in girls during the intervening period. This was present in all ethnic subgroups and was significant for white boys and girls, for whom the numbers were large, and also for Mediterranean boys. Lack of significance in the other ethnic subgroups might be a reflection of the smaller numbers in each. It is likely, however, that an increase in BMI among primary school aged children began about 10 years before the ACHPER 1985 survey. Analyses of surveys of Queensland schoolchildren undertaken in 1911, 1950, and 1976 showed no significant change in BMI from 1911 to 1950, but a definite small increase in $1976 . .^{15}$ Our findings are consistent with an acceleration of this effect. It is now well documented that weight patterns in childhood reflect those in adulthood, with obesity tracking particularly strongly. ${ }^{1-3}$ We have shown previously that levels of apolipoprotein B (apo B) are significantly increased in overweight children, ${ }^{4}$ and that circulating apo $\mathrm{B}$ is correlated strongly with ethnicity in the 
cosmopolitan population of southeastern Sydney. ${ }^{5}$ Apo B is the carrier protein for the atherogenic low density lipoprotein (LDL) cholesterol, and circulating concentrations reflect $\mathrm{LDL}$ cholesterol concentrations ${ }^{16}$ and cardiovascular risk. ${ }^{17}$ Indeed, in our earlier study, increased apo B concentrations in children were predictive of an increased risk of coronary vascular events in older family members-even across a generation gap, ${ }^{6}$ effects likely to be both genetically and environmentally mediated. However, the rapidity of the development of the present changes indicates that lifestyle alterations affecting diet and exercise levels are the likely cause. An inverse relation between physical activity and BMI has been documented for Belgian children, ${ }^{18}$ and also for children in Singapore, in whom an increase in BMI was also associated with an adverse lipid profile, ${ }^{19}$ as we have shown for Australian children. ${ }^{4}$

In relation to our findings, it is important to acknowledge the limitations in the use of BMI as an index of increased body weight in growing children. ${ }^{20-22}$ Total body fat measurement by magnetic resonance imaging and measurements of triceps and subscapular skinfolds provide more accurate estimations, but are suited more for use in small scale studies and clinical settings. ${ }^{23} 24$ Despite these limitations, the extensive study of Lazarus and colleagues reveals a close association between $\mathrm{BMI}$ and adiposity in Australian children ${ }^{25}$; and in Busselton (Western Australia), Kelly et al found that most children who were heavier than their non-obese peers at age 6 years or over became overweight in adulthood. ${ }^{26}$ Furthermore, in German children of the same age as those in our study, the BMI provided a good estimate of total body fat measured by magnetic resonance imaging ${ }^{27}$; and in Italian children the BMI was also strongly associated with total body fat. ${ }^{28}$ There is a consistent relation between BMI and adverse lipid profiles in children, which is highly relevant to adult onset disease. ${ }^{2} 461629$ Further to the data we have provided from Australian families on atherogenic lipid profiles in children, ${ }^{6}$ there are now recently reported important postmortem findings. Among children and young adults who died suddenly, mainly from trauma, and for whom antemortem risk factor profiles were available, Berenson and colleagues have documented strong correlations between BMI and the presence of fibrous plaques $(p<0.01)$ and fatty streaks $(\mathrm{p}<0.0001)$ in coronary arteries. ${ }^{29}$ Therefore, we suggest that, despite its limitations, documentation of the BMI provides information relevant to health outcomes and also an index of adiposity that facilitates comparisons between populations and ethnic groups within them.

In summary, our study identifies current ethnic and age related differences in BMI among primary school aged Sydney children, which underscore the need to control for these when analysing the present cosmopolitan Australian population. The data are also consistent with an increase in weight relative to height in
Sydney primary school aged boys and girls over the past $10-15$ years. Because increased BMI and obesity tracks from childhood to adulthood, with potentially adverse long term health effects, these findings signal a need for prevention. The results of our study also emphasise a recent editorial comment that there is now a "clear case for redoubling efforts to promote population wide good health practices in children and young adults that may help to decrease the risk of future cardiovascular disease". ${ }^{30}$

The ACHPER data were obtained from the Australian health and fitness survey (1985), jointly funded by the Commonwealth Department of Sport Recreation and Tourism, the Commonwealth Schools Commission, the Commonwealth Department wealth Schools Commission, the Commonwealth Department of Health and the National Heart Foundation of Australia. We also wish to thank our heart health programme dieticians $M$
Meischke, R Scott, and K Lobley for their assistance in collecting height and weight data.

1 Krauss RM, Winston M, Fletcher BJ, Grundy SM. Obesity: impact on cardiovascular disease. Circulation 998;98:1472-6.

2 Srinivasan SR, Bao W, Wattigney WA, et al. Adolescent overweight is associated with adult overweight and related multiple cardiovascular risk factors: the Bogalusa heart study. Metabolism 1996;45:235-40.

3 Whitaker RC, Wright JA, Pepe MS, et al. Predicting obesity in young adulthood from childhood and parental obesity. $N$ Engl f Med 1997;337:869-73.

4 Wilcken DEL, Lynch JF, Marshall MD, et al. Relevance of body weight to apolipoprotein levels in Australian children. Med F Aust 1996;164:22-5.

5 Lynch JF, Marshall MD, Wang XL, et al. Apolipoprotein screening in Australian children: feasibility and the effect of age, sex, and ethnicity. Med f Aust 1998;168:61-4.

6 Wilcken DEL, Wang XL, Greenwood J, et al. Lipoprotein (a) and apolipoproteins B and A-1 in children and coronary vascular events in their grandparents. $\mathcal{F}$ Pediatr coronary vascular

7 Australian Health and Fitness Survey 1985. The Australian Council for Health Physical Education and Recreation Inc. PO Box 126, Hawker, ACT 2614.

8 Rosner B, Prineas R, Loggie J, Daniels SR. Percentiles for body mass index in US children 5-17 years of age. F Pediatr 1998;132:211-22.

9 Seidell JC. Obesity in Europe: scaling an epidemic [review]. Int $\mathcal{F}$ Obes Relat Metabol Disord 1995;19(suppl 3):S1-4.

10 Unwin N, Harland J, White M, et al. Body mass index, waist circumference, waist-hip ratio, and glucose tolerance in Chinese and Europid adults in Newcastle UK. $\mathcal{F}$ Epidemiol Community Health 1997;51:160-6.

11 Al-Shammari SA, Khoja TA, al-Subaie AS. Transcultural attitude towards being overweight in patients attending health centers Riyadh, Saudi Arabia. Family Practice Research fournal 1994;14:149-56.

12 Rolland-Cachera MF, Cole TJ, Sempe M, Tichet J, Rossignol C, Charraud A. Body mass index variations: centiles from birth to 87 years. Eur $\mathcal{f}$ Clin Nutr 1991;45:13-21

13 De Spiegelaera M, Dramnais M, Hennart P. The influence of socioeconomic status on the incidence and evolution of obesity during early adolesence. Int f Obes Relat Metab Disord 1998;22:268-74.

14 Blane D, Hart CL, Smith GD, et al. Association of cardiovascular disease risk factors with socio-economic position during childhood and during adulthood. BMF 1996;313:1434-8.

15 Dugdale AE, O'Hara V, May G. Changes in body size and fatness of Australian schoolchildren 1911-1976. Australian Paediatric fournal 1983;19:14-17.

16 Dennison BA, Kikuchi DA, Srinivasan SR, et al. Measurement of apolipoprotein B as a screening test for identifying children with elevated low-density lipoprotein cholesterol. children with elevated low-de

17 Gotto AM Jr. Primary and secondary prevention of coronary artery disease. Curr Opin Lipidol 1992;7:553-62.

18 Guillaume M, Lapidus L, Bjorntorp P, Lambert A. Physical activity, obesity, and cardiovascular risk factors in children. The Belgian Luxembourg child study II. Obes Res 1997;5: 549-56.

19 Schmidt GJ, Stensel DJ, Walkuski JJ. Blood pressure, lipids, lipoproteins, body fat and physical activity of Singapore children. F Pediatr Child Health 1997;33:484-90.

20 Cole TJ. A method for assessing age standardised weightfor-height in children seen cross sectionally. Ann Hum Biol 1979;7:457-73

21 Poskitt EME. Defining childhood obesity: the relative body mass index. Acta Paediatr 1995;84:961-3

22 Widdowson EM. Changes in body proportion and body composition with growth. In: Davies JA, Dobbing J, eds. Scientific foundations of paediatrics. London: Heinemann Scientific foundat
$1974 ; 153-63$ 
23 Chan YL, Leung SSF, Lam WWM, Peng XH, Metreweli C. Body fat estimation in children by magnetic resonance imaging, bioelectrical impedance, skinfold and body mass index: a pilot study. F Paediatr Child Health 1998;34:22-8.

24 Krauss RM, Winston M, Fletcher BJ, Grundy SM. Obesity. Impact on cardiovascular disease. Circulation 1998;98: 1472-6.

25 Lazarus R, Baur L, Webb K, et al. Adiposity and body mass indices in children: Benn's index and other weight for height indices as measures of relative adiposity. Int 7 Obes Relat Metab Disord 1996;20:406-12.

26 Kelly P, Sullivan D, Bartsch M, Gracey M, Ridout S. Evolution of obesity in young people in Busselton, Western Australia. Med f Aust 1984;141:97-9.
27 Schaefer F, Georgi M, Wuhl E, Scharer K. Body mass index and percentage fat mass in healthy German school children Pelat Misord 1998;22: $461-9$

28 Pietrobelli A, Faith MS, Allison DB, gallaher D, Chiumello G, Heymsfield SB. Body mass index as a measure of adiposity among children and adolescents: a validation study. F Pediatr 1998;132:204-10.

29 Berenson GS, Srinivasan SR, Bao W, et al. Association between multiple cardiovascular risk factors and atherosclerosis in children and young adults. N Engl f Med 1998; 338:1650-6.

30 Gaziano JM. When should heart disease prevention begin? N Engl f Med 1998;338:1690-1.

\section{STAMPS IN PAEDIATRICS}

\section{Stamps in paediatrics}

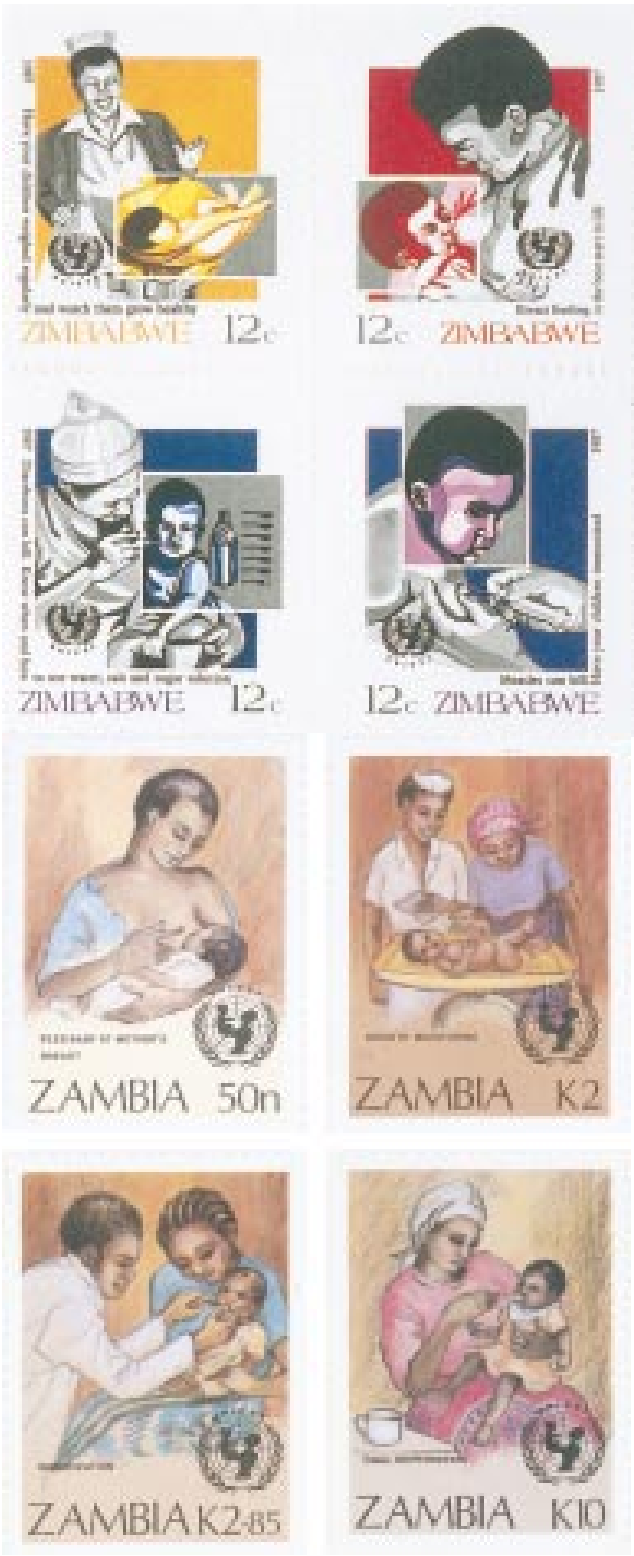

Over the next months the Archives of Disease in Childhood and the Fetal and Neonatal edition will feature a series of "Stamps in paediatrics". Postage stamps and cancellation marks provide an excellent advertising medium, which has been fully utilised over the years in promoting health care and public awareness campaigns. In terms of medical postage stamps, paediatric and child health/welfare issues have been some of the most prolific, particularly in the less well developed countries, and are aimed at raising funds for child welfare organisations or disseminating information to the population regarding child health issues. Many national and international organisations such as UNICEF, Save the Children Fund, and the World Health Organisation have used postage stamp advertising to promote their individual or collective campaigns.

The most frequent paediatric campaigns featured on the stamps have been the promotion of breast feeding/nutrition, growth monitoring, immunisation, and oral rehydration therapy-well illustrated by the two sets of UNICEF stamps from Zimbabwe (1987) and Zambia (1988). Both issues were part of the Child Survival Campaign and emphasise one of the main features of the successful use of this communication medium. Pictorial rather than linguistic messages are the most effective as they are understood equally well across all national and international boundaries and do not require literacy to be widely and easily interpreted.

Selections of paediatric stamps from around the world covering a range of aspects in child health and welfare will be incorporated in the future issues.

M K DAVIES Consultant Cardiologist, Selly Oak Hospital, Birmingham, UK

A J MAYNE Consultant Paediatrician, Sandwell Hospital, Birmingham, UK 